\title{
Eco-Friendly Sustainable Poly(benzoxazine-co-urethane) with Room-Temperature-Assisted Self-Healing Based on Supramolecular Interactions
}

\author{
Salendra Sriharshitha, Krishnamoorthy Krishnadevi, ${ }^{*}$ Subramani Devaraju,* \\ Venkatesan Srinivasadesikan, and Shyi-Long Lee
}

Cite This: ACS Omega 2020, 5, 33178-33185

Read Online

ABSTRACT: This work is an attempt to develop bio-based ecofriendly poly(benzoxazine-co-urethane) [poly(U-co-CDL-aee)] materials using cardanol-based benzoxazines (CDL) and hexamethylene diisocyanate (HMDI) to check their self-healing ability and thermal properties. CDL monomers were synthesized using cardanol, amino ethoxyethanol (aee) or 3-aminopropanol (3-ap), and paraformaldehyde through the Mannich reaction. Later, CDLaee or CDL-3-ap monomers were copolymerized with a urethane precursor (HMDI), followed by ring-opening polymerization through thermal curing. The thermal properties of poly(U-co$\mathrm{CDL}$ ) were evaluated by differential scanning calorimetry (DSC) and thermogravimetric analysis (TGA). The self-healing behavior of the bio-based poly(U-co-CDL) was checked by applying a mild

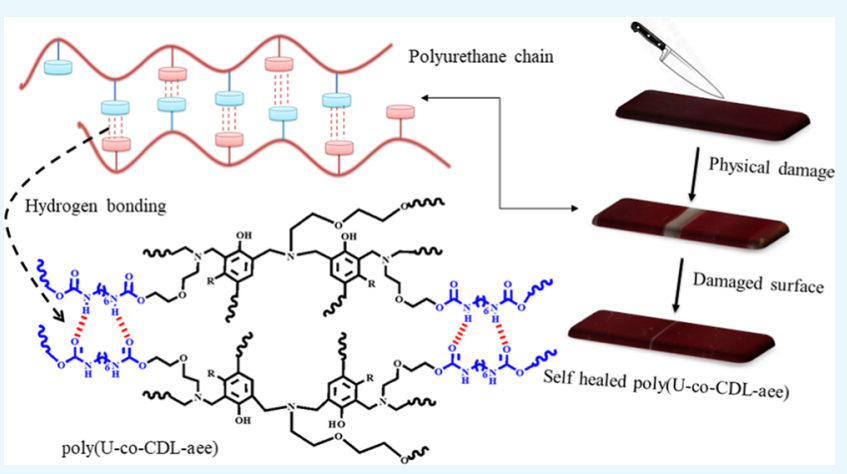
external pressure. The results revealed that the developed poly(U-co-CDL) showed repeatable self-healing ability due to supramolecular hydrogen-bonding interactions. Further, the self-healing ability of poly(U-co-CDL) was studied using density functional theory (DFT). From the above results, the developed material with superior self-healing ability can be used in the form of self-healing coatings and composites for various applications with extended shelf-life and reliability.

\section{INTRODUCTION}

Self-healing methods are common to nature; for example, damaged or lost tissues and organs may be regained or regenerated in most of the living organisms. Inspired by this concept, scientists have attempted to develop synthetic selfhealing polymeric materials in the last two decades in comparison with traditional polymeric materials. Due to their in-built capability to revamp physical damage triggered by both environmental and mechanical factors, ${ }^{1-15}$ the self-healing abilities of polymeric materials not only extend their service life but also enhance the reliability of products in various applications; hence, this approach may surely be able to reduce the usage of available resources. ${ }^{1,2}$ Therefore, many approaches are adopted for the development of self-healing materials. Generally, they are classified into autonomous selfhealing and nonautonomous self-healing systems. Autonomous systems do not need external triggers for the self-healing ability, whereas nonautonomous systems utilize external triggers including temperature, light, $\mathrm{pH}$, redox, etc. ${ }^{1,2}$ In addition, self-healing materials can also be further classified into intrinsic self-healing and extrinsic self-healing systems. Extrinsic self-healing polymeric systems work in the presence of external healing agents like microcapsules or fibers, which heal the cracked or damaged portion at once. On the contrary, intrinsic self-healing materials undergo repeated multiple healings without any external healing agents. ${ }^{1,2,8}$ These types of intrinsic self-healing polymeric materials are generally designed through dynamic reversible cross-linking by either covalent interactions, such as the Diels-Alder/retro-DielsAlder reaction, ${ }^{1,15}$ trans-esterification, ${ }^{12}$ photodimerization, ${ }^{13}$ acylhydrazone linkage, ${ }^{14}$ disulfide linkage, ${ }^{8,15}$ etc., or noncovalent supramolecular interactions, which include $\mathrm{H}$ bonding, ${ }^{14-16} \pi-\pi$ stacking, ${ }^{16}$ metal-ion, ${ }^{13}$ etc. Mostly, thermoplastic polymers have been utilized for self-healing applications. Generally, thermoset polymers are single-use polymers that cannot be used multiple times. If damaged, they have to be replaced with new polymeric materials.

Among the thermosets, polybenzoxazines are a new class of phenolic resins with good thermal and mechanical properties that allow overcoming several drawbacks of traditional

Received: October 3, 2020

Accepted: December 2, 2020

Published: December 14, 2020 


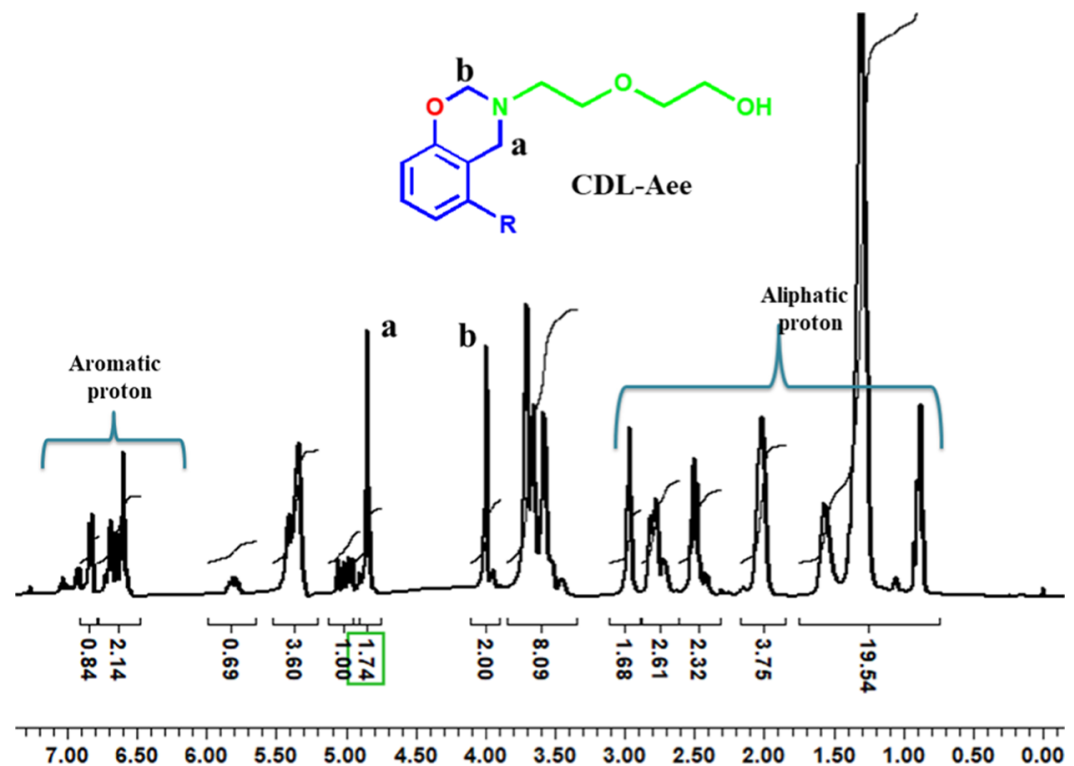

Figure 1. ${ }^{1} \mathrm{H}$ NMR spectrum of CDL-aee.

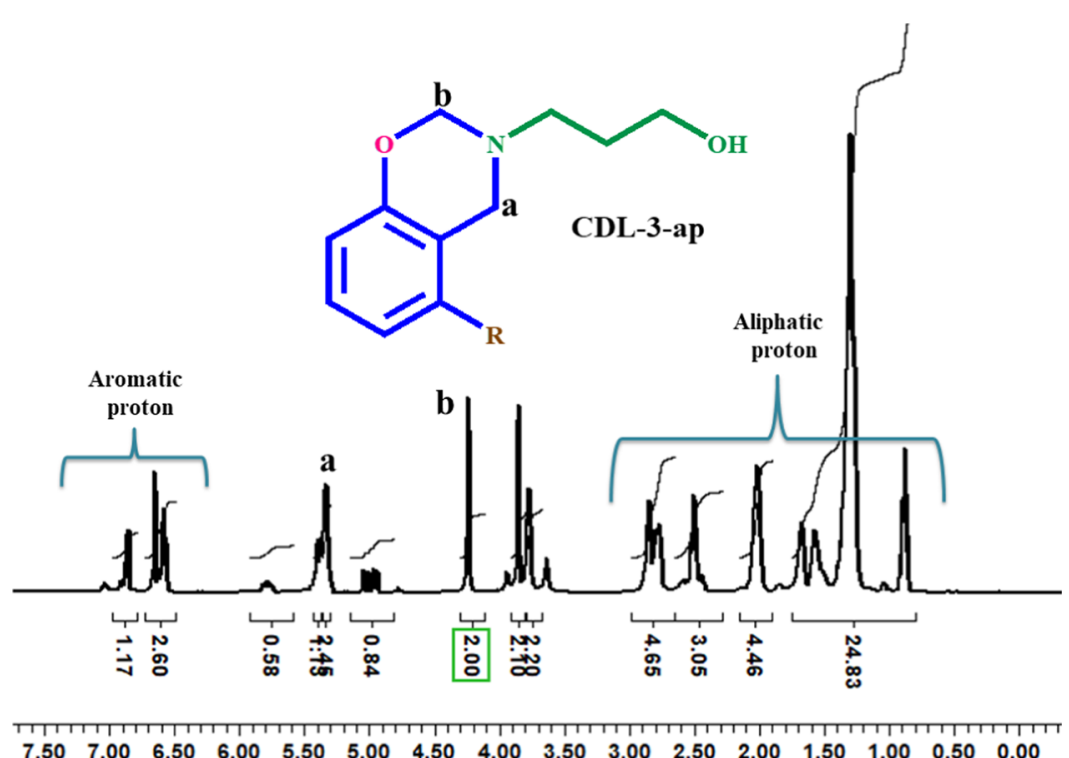

Figure 2. ${ }^{1} \mathrm{H}$ NMR spectrum of CDL-3-ap.

phenolic resins. Also, this class has many added advantages such as a variety of molecular designs, low dielectric constant, high moisture resistance, high heat resistance, dimensional stability, good flame retardancy, excellent thermal stability, mechanical properties, and high residual char ratio. ${ }^{12,13,17-23}$ Though polybenzoxazines have been utilized in various applications, the usage of polybenzoxazines in self-healing materials has barely been reported. Only limited studies have been published on self-healing. Yagci's research group developed a self-healing material using poly(propyleneoxide)based benzoxazine with varying weight ratios of acidfunctionalized benzoxazine by supramolecular interactions. ${ }^{24}$ The same group reported the self-healing behavior of polybenzoxazines based on both metal-ligand interactions and supramolecular attraction using a polydimethylsiloxanebased benzoxazine matrix. ${ }^{25}$ The same research group reported that benzoxazine monomers can be used as self-healing agents for a polysulfone (PSU) matrix. ${ }^{26}$ The self-healing property of polybenzoxazine by photo-induced coumarine dimerization ${ }^{27}$ has also been reported, and reusable and self-healable polybenzoxazines have been developed by the inverse vulcanization approach. ${ }^{15}$ Xiangdong Liu et al. developed self-healing polybenzoxazine using succinic anhydride and bisphenol-F benzoxazine through trans-esterification at a temperature of $140{ }^{\circ} \mathrm{C}$ in the presence of zinc acetate as a catalyst. $^{28}$ The reported polybenzoxazine materials with selfhealing ability almost always involved multiple and nontrivial steps. To the best of our knowledge, to date, there has been no report on eco-friendly bio-based polybenzoxazines with selfhealing or self-repairing ability in the literature. Here, an attempt has been made to develop eco-friendly bio-based polybenzoxazine-co-polyurethane matrices using cardanolbased benzoxazine derivatives (CDL) and hexamethylene diisocyanate (HMDI) and check their self-healing capability and thermal properties. The self-healing behavior of the biobased poly(U-co-CDL) is checked by applying a mild external 
pressure without use of any external agents/trigger. The developed poly(U-co-CDL) shows good self-healing properties due to supramolecular action and inter- and intramolecular hydrogen-bonding interactions. Further, the self-healing ability of poly (U-co-CDL) is due to the supramolecular attraction and inter- and intramolecular hydrogen-bond interactions, which was revealed theoretically by DFT studies. The developed lowcost and environment-friendly self-healing poly(U-co-CDL) will be useful in various high-performance applications including coatings, automobile, printed circuit boards, etc. with a long shelf-life.

\section{RESULTS AND DISCUSSION}

Structural Determination of the Composites. The structures of the synthesized renewable cardanol-based benzoxazine monomers CDL-aee and CDL-3-ap were confirmed with the help of ${ }^{1} \mathrm{H}$ NMR shown in Figures 1 and 2. From the NMR spectra of Figure 1, the peak that appeared at $4.01 \mathrm{ppm}$ corresponds to $\mathrm{Ph}-\mathrm{CH}_{2}-\mathrm{N}$ and the absorption peak at $4.93 \mathrm{ppm}$ is related to the $\mathrm{O}-\mathrm{CH}_{2}-\mathrm{N}$ protons of the oxazine ring. The appearance of peaks between 0.8 and 3.0 ppm corresponds to alkyl side-chain protons of cardanol. The peaks between 5.2 and $5.5 \mathrm{ppm}$ represent the olefinic protons of cardanol. The peaks that appeared between 3.4 and $3.7 \mathrm{ppm}$ represent protons of aminoethoxy ethanol. The peaks that appeared in the range of $6.6-6.8 \mathrm{ppm}$ represent aromatic protons.

The ${ }^{1} \mathrm{H}$ NMR spectrum of CDL-3-ap is shown in Figure 2. The peaks that appeared at $4.2 \mathrm{ppm}$ and $5.3 \mathrm{ppm}$ correspond to the protons of $\mathrm{Ph}-\mathrm{CH}_{2}-\mathrm{N}$ and $\mathrm{O}-\mathrm{CH}_{2}-\mathrm{N}$, respectively. The alkyl side-chain protons of cardanol peaks appeared between 0.8 and $3.0 \mathrm{ppm}$. The triplet peak that appeared at 3.8 ppm corresponds to $-\mathrm{C}-\mathrm{CH}_{2}-\mathrm{O}$ in the aminopropanol group. The aromatic protons appeared in the range between 6.6 and $6.8 \mathrm{ppm}$.

The Fourier transform infrared (FTIR) spectra of cardanolbased benzoxazines are presented in Figure 3. The appearance

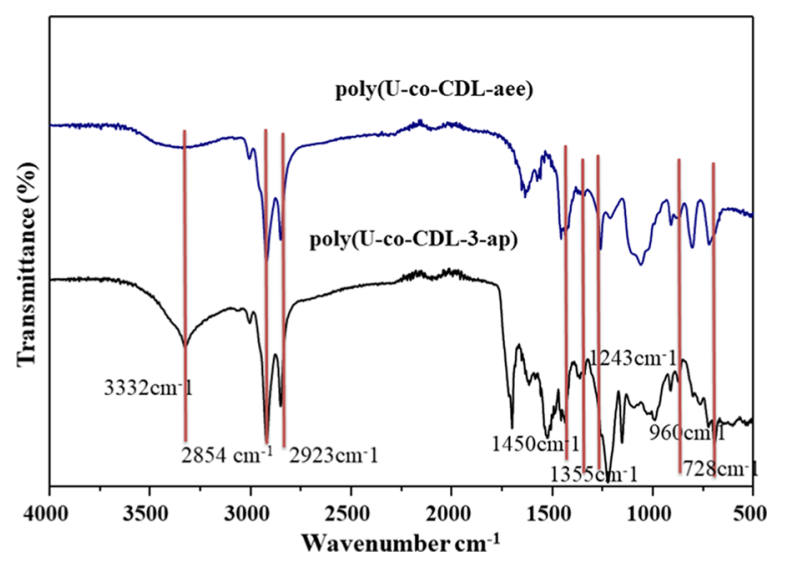

Figure 3. FT-IR spectra of CDL-aee and CDL-3-ap monomers.

of a vibration band at $960 \mathrm{~cm}^{-1}$ corresponds to the oxazine ring, which confirms the formation of the benzoxazine ring. ${ }^{19,29,30}$ In the oxazine ring, the $\mathrm{C}-\mathrm{H}$ out-of-plane bending is observed at $728 \mathrm{~cm}^{-1}$. The vibration peaks around 1055$1118 \mathrm{~cm}^{-1}$ represent the symmetric stretching of $\mathrm{C}-\mathrm{O}-\mathrm{C}$, and the peak at $1243 \mathrm{~cm}^{-1}$ represents the asymmetric stretching of $\mathrm{C}-\mathrm{O}-\mathrm{C}$; also, the peak at $1355 \mathrm{~cm}^{-1}$ represents the $\mathrm{C}-\mathrm{N}-\mathrm{C}$ vibration. Further, the characteristic absorption peaks that appeared at around 2854 and $2923 \mathrm{~cm}^{-1}$ correspond to the asymmetric and symmetric stretching vibrations of $\mathrm{CH}_{2}$ of the oxazine ring as well as the alkyl side chain of cardanol. The peak at $3440 \mathrm{~cm}^{-1}$ shows the presence of the hydroxyl group in CDL.

The successful formation of renewable cardanol-based polybenzoxazines and poly(U-co-CDL) was studied using FT-IR, and the results are shown in Figure 4. From Figure 4,

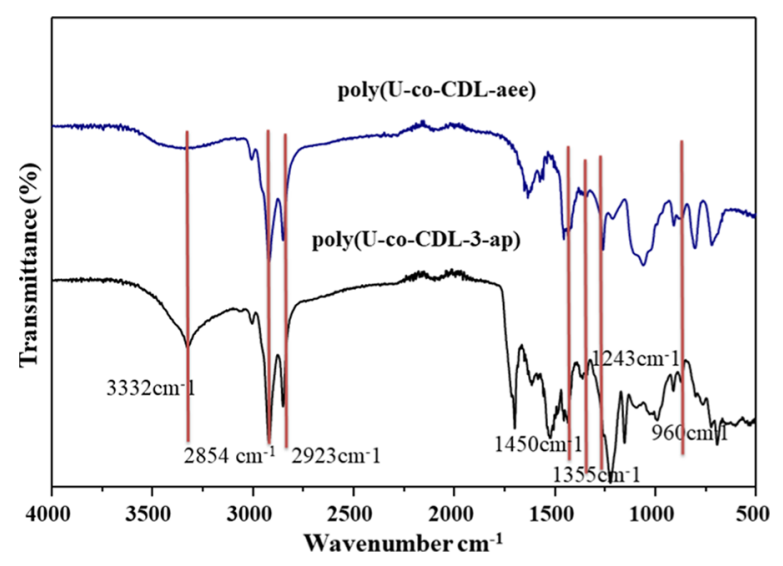

Figure 4. FT-IR spectra of poly(U-co-CDL-aee) and poly(U-co-CDL3-ap).

the disappearance of the absorption band at $960 \mathrm{~cm}^{-1}$ and the appearance of a new peak at $1450 \mathrm{~cm}^{-1}$ are related to the formation of a tri- to tetra-substituted benzene ring, which confirms the occurrence of ring-opening polymerization of CDL. ${ }^{31}$ The appearance of new peaks at 1254 and $1533 \mathrm{~cm}^{-1}$ represents the bending vibration of $\mathrm{N}-\mathrm{H}$ and stretching vibration of $\mathrm{C}-\mathrm{N}$, respectively, which confirms the urethane linkage due to the introduction of HMDI into CDL. Further, the appearance of a peak at $1702 \mathrm{~cm}^{-1}$ shows the stretching vibration of $\mathrm{C}=\mathrm{O}$, and also the peak at $3332 \mathrm{~cm}^{-1}$ represents the $\mathrm{NH}$ stretching corresponding to the urethane linkage in CDL.

\section{THERMAL PROPERTIES OF MONOMERS AND COMPOSITES}

The curing properties of sustainable benzoxazines were studied with the DSC technique, and the curing thermogram is depicted in Figure 5. The DSC thermogram of sustainable benzoxazines was recorded at a heating rate of $10{ }^{\circ} \mathrm{C} / \mathrm{min}$ under an inert atmosphere from 30 to $300{ }^{\circ} \mathrm{C}$. From the DSC thermogram in Figure 5, the curing behavior of sustainable benzoxazines was observed from the single exothermic peak, which is attributed to the ring opening of the benzoxazine ring during thermal curing. Temperature peaks (exotherm maxima, $T_{\mathrm{p}}$ ) were observed at 239 and $238^{\circ} \mathrm{C}$ for CDL-aee and CDL3-ap (monomers) benzoxazines, respectively (Table 1 ). Generally, the curing of cardanol-based benzoxazine reveals the exothermic peak between 250 and $295{ }^{\circ} \mathrm{C}$, ${ }^{32}$ while in our work, the curing temperature of sustainable benzoxazines decreased to $238-239{ }^{\circ} \mathrm{C}$. This may be due to the hydroxylterminated CDL that acts as a self-catalyst to decrease the curing temperature of the resulting cardanol benzoxazine monomers.

Thermogravimetric analysis (TGA) provides valuable information with regard to the thermal stability of materials and the nature of degradation by measuring the weight loss at 


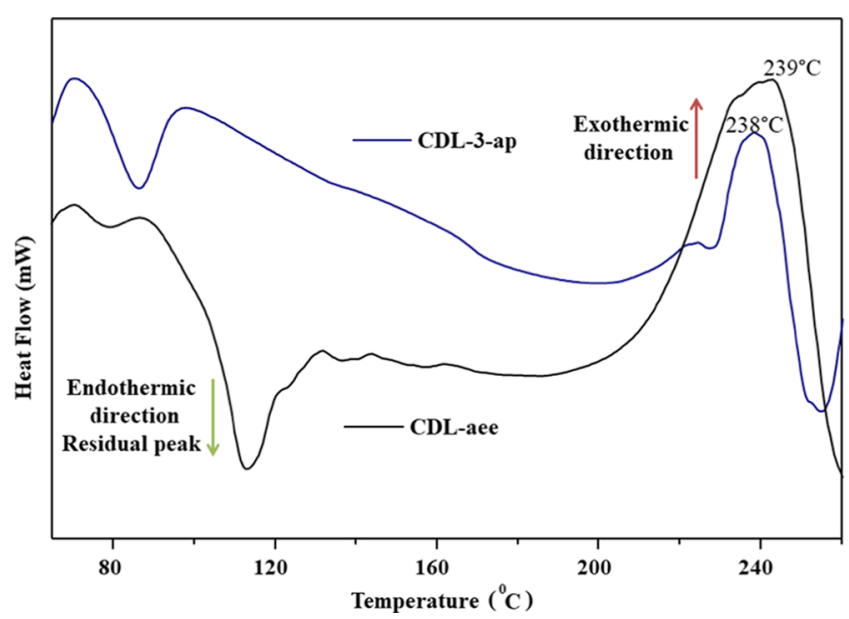

Figure 5. DSC thermogram of CDL-aee and CDL-3-ap.

Table 1. Thermal Properties of Cardanol-Based Benzoxazines of Poly(U-co-CDL-3-ap) Copolymers

\begin{tabular}{|c|c|c|c|c|c|c|c|}
\hline \multirow[b]{2}{*}{$\begin{array}{l}\text { cardanol- } \\
\text { based } \\
\text { benzoxazines }\end{array}$} & \multicolumn{3}{|c|}{ curing behavior } & \multirow[b]{2}{*}{$\begin{array}{c}5 \% \\
\text { weight } \\
\text { loss } \\
\left({ }^{\circ} \mathrm{C}\right)\end{array}$} & \multirow[b]{2}{*}{$\begin{array}{c}10 \% \\
\text { weight } \\
\text { loss } \\
\left({ }^{\circ} \mathrm{C}\right)\end{array}$} & \multirow[b]{2}{*}{$\begin{array}{l}T_{\max } \\
\left({ }^{\circ} \mathrm{C}\right)\end{array}$} & \multirow[b]{2}{*}{$\begin{array}{l}\text { char } \\
\text { yield \% } \\
\text { at } \\
800{ }^{\circ} \mathrm{C}\end{array}$} \\
\hline & $\underset{\left({ }^{\circ} \mathrm{C}\right)}{T_{\mathrm{i}}}$ & $\underset{\left({ }^{\circ} \mathrm{C}\right)}{T_{\mathrm{C}}}$ & $\underset{\left({ }^{\circ} \mathrm{C}\right)}{T_{\mathrm{f}}}$ & & & & \\
\hline CDL-aee & 203 & 239 & 254 & 313 & 365 & 492 & 12 \\
\hline CDL-3-ap & 223 & 238 & 253 & 256 & 343 & 489 & 7 \\
\hline \multicolumn{3}{|c|}{ poly(U-co-CDL-3-aee) } & & 285 & 301 & 463 & 3 \\
\hline \multicolumn{3}{|c|}{ poly(U-co-CDL-3-ap) } & & 256 & 274 & 467 & 4 \\
\hline
\end{tabular}

each instant. The thermal stability of cardanol-based polybenzoxazines was studied with the help of TGA, and the results are displayed in Figure $6 \mathrm{a}, \mathrm{b}$ and Table 1. For cardanolbased polybenzoxazines with two different amines (CDL-aee and CDL-3-ap), the 5\% weight loss temperature $\left(T_{5}\right)$ was noticed at 313 and $256{ }^{\circ} \mathrm{C}$ (Figure 6a) and the maximum degradation temperature $\left(T_{\max }\right)$ was 492 and $489{ }^{\circ} \mathrm{C}$, respectively. The char yield of CDL-aee- and CDL-3ap-based polybenzoxazines was obtained as 12 and 7\%, respectively, at $800{ }^{\circ} \mathrm{C}$. Further, the thermal stability of poly(U-co-CDL) copolymers was checked with TGA and is depicted in Figure 6. From the TGA curve, the maximum degradation temperature obtained for 1:1 weight percentage ratio of poly(U-co-CDL-3aee) and poly(U-co-CDL-3-ap) was 463 and $467{ }^{\circ} \mathrm{C}$ (Figure $6 \mathrm{~b})$ and the char yield was 3 and $4 \%$, respectively. The char yield percentages of the above blends decreased to below 5\% (compared to the neat polybenzoxazine) due to the aliphatic polyurethane backbone in poly(U-co-CDL) copolymers. ${ }^{1}$

Self-Healing Behavior of Cured Samples. Self-healing in supramolecular polymers (Figure 7) can be explained by the

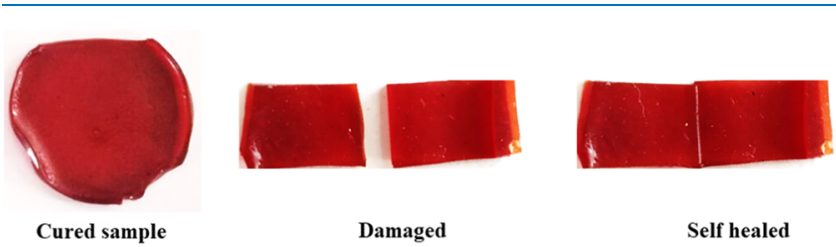

Figure 7. Thermally cured poly(U-co-CDL-aee) of damaged and selfhealed samples.

following basic steps: First, the undamaged materials consisting of polymer chains with attached inter- and intramolecular hydrogen bonds form a network, ${ }^{33}$ and these bonds are able to connect and reconnect via a reversible "sticker-like" behavior. Thus, the strength of the polymeric materials is imparted by the "stickiness" of supramolecular hydrogen bonds, which is crucial for the formation of specific interactions between the bonds. $^{22}$ To justify the concept, the self-healing behavior of our polymers was tested on cured materials by applying a mild external pressure, and the test was recorded in the form of a video clipping (Video S1, supporting information). The prepared material film with $2 \mathrm{~mm}$ thickness and $2 \mathrm{~cm}$ length was taken and a cut was made in the middle to separate them into two equal halves. The equal parts were forced to join adjacently by applying a mild external pressure sideward to repair the damaged site. This process was repeated for 3-4 trials, and the material still showed good self-healing behavior.

Thus, poly(U-co-CDL-aee) containing the urethane group motif shows complete healing (by applying a mild external pressure), probably caused by the delayed elasticity introduced by the supramolecular attraction; also, the inter- and intermolecular hydrogen bonding between the phenolic hydroxyl group and the urethane group present in the materials is responsible for self-healing. The $\mathrm{O}-\mathrm{H} \cdots \mathrm{O}, \mathrm{N}-$ $\mathrm{H} \cdots \mathrm{N}$, and $\mathrm{N}-\mathrm{H} \cdots \mathrm{O}$ types of hydrogen bonding were present in the material, and this was theoretically demonstrated using computational studies.

Computational Studies. The model calculation of polymeric chain and its interactions was examined using the state-of-the-art density functional theory (DFT) implemented
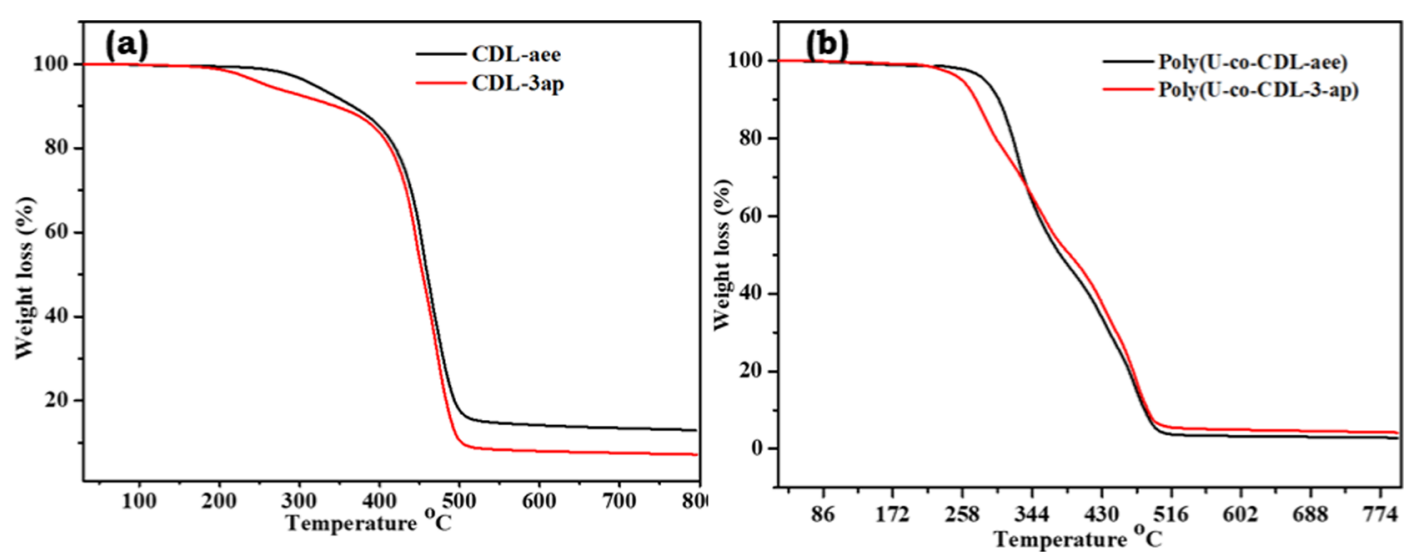

Figure 6. (a) TGA spectra of CDL-aee and CDL-3-ap and (b) poly(U-co-CDL-3-aee) and poly(U-co-CDL-3-ap) copolymers. 


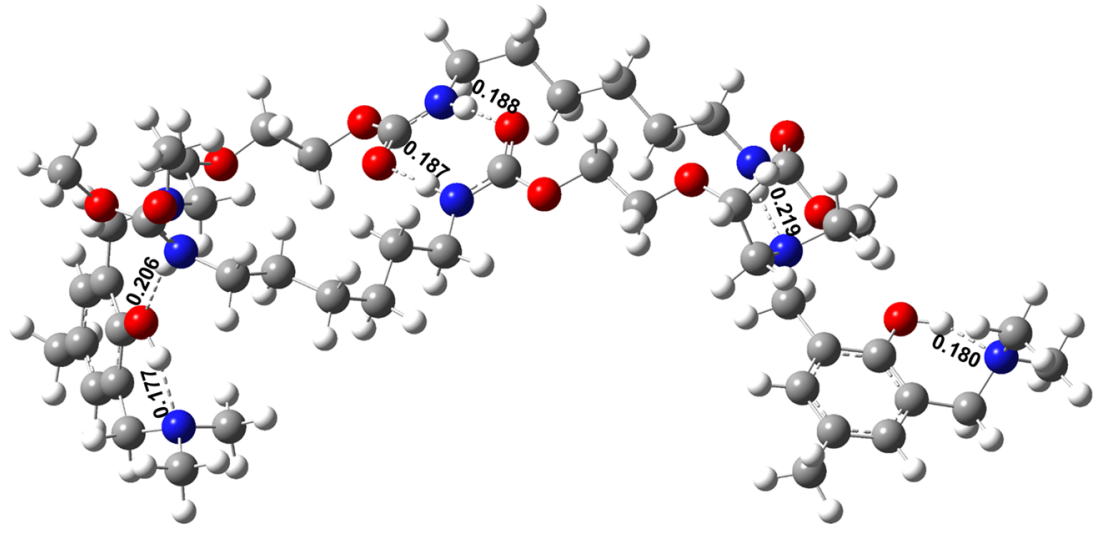

Figure 8. Molecular structure of poly(U-co-CDL-3-aee) optimized at the B3LYP/6-31g(d,p) level in the gas phase.

in the Gaussian $09^{34}$ suite of program. The monomer of poly(U-co-CDL-aee) was optimized at the B3LYP/6-31g$(\mathrm{d}, \mathrm{p})^{35-38}$ level in the gas phase. The optimized structure was confirmed without any imaginary frequency through frequency calculations. Moreover, the monomers were duplicated and added in the Gaussian view to optimize the complex structure at the same level of theory. The optimized complex structure is shown in Figure 8. The hydrogen bond lengths are indicated by the dotted lines. Both the monomers interacted closely due to six strong hydrogen bonds, i.e., O$\mathrm{H} \cdots \mathrm{O}, \mathrm{N}-\mathrm{H} \cdots \mathrm{N}$, and $\mathrm{N}-\mathrm{H} \cdots \mathrm{O}$ types of strong hydrogen bonds. These types of hydrogen bonds are reported in the literature as strong and responsible for the stability of the complexes. $^{39-42}$ The lengths of the hydrogen bonds are observed to be $1.8-2.0 \mathrm{~nm}$. In the optimized complex, the center part of the polymer formed two hydrogen bonds, N$\mathrm{H}$... O type, which are observed to be strong as compared with the hydrogen bonds at both ends. Also, the complex formed a linear chain and elongated while forming a complex. It was experimentally observed that when a load was placed on the complex, applying a mild pressure, no cracks were formed due to the above-mentioned strong hydrogen bonds. Additionally, the interaction energy for the complex was calculated to be $29.99 \mathrm{kcal} / \mathrm{mol}$. The strong interaction energy and the large number of strong hydrogen bonds in the complex are responsible for self-healing while testing the material with a mild external pressure.

\section{CONCLUSIONS}

In this work, a sustainable poly(U-co-CDL) copolymer was successfully developed using cardanol-based benzoxazines (CDL) and HMDI as a urethane precursor with autonomous self-healing ability. Cardanol-based benzoxazines were synthesized by the Mannich reaction using cardanol, AEE or 3AP, and paraformaldehyde. The structures of CDL monomers were confirmed by FT-IR and NMR. The developed CDL and poly(U-co-CDL) matrices were checked for their thermal stability. The self-healing behavior was demonstrated on cured films. The autonomous self-healing ability was due to the supramolecular attraction and inter/intramolecular hydrogenbond interactions in the poly(U-co-CDL) matrices, which was revealed theoretically using DFT studies. The developed renewable, eco-friendly, and cost-effective poly(U-co-CDL) copolymer materials are useful for further expanding the use of benzoxazines in various high-performance applications with good reliability and long shelf-life.

\section{EXPERIMENTAL SECTION}

Materials. 2-(2-Aminoethoxy) ethanol (aee), 3-aminopropanol (3-ap), and hexamethylene diisocyanate (HMDI) were procured from Sigma-Aldrich, India. Paraformaldehyde, 1,4-dioxane, ethyl acetate, anhydrous sodium sulfate $\left(\mathrm{Na}_{2} \mathrm{SO}_{4}\right)$, ethanol, dichloromethane, and sodium hydroxide $(\mathrm{NaOH})$ were purchased from Sisco Research Laboratories (SRL), India, and were used without further purification. Thanks are due to Satya Cashew Chemicals (P) Ltd., for providing cardanol as a complimentary sample.

Measurements. FT-IR spectra of benzoxazine and polybenzoxazine samples were obtained with an Agilent Cary 630 ATR spectrometer. About $10 \mathrm{mg}$ of the sample was loaded in the ATR spectrometer, with a minimum of 16 scans collected for each sample at a resolution of $\pm 4 \mathrm{~cm}^{-1}$. ${ }^{1} \mathrm{H}$ NMR spectra were recorded with a Bruker $400 \mathrm{MHz}$ using an 8000 $\mathrm{Hz}$ spectral width, a relaxation delay of $3.5 \mathrm{~s}$, a pulse width of $45,32 \mathrm{~K}$ data points, $\mathrm{CDCl}_{3}$ as a solvent, and tetramethylsilane (TMS) as an internal standard, with a minimum of 32 scans collected for each sample. Differential scanning calorimetry (DSC) measurements were carried out using a Hitachi DSC 7020. The instrument was calibrated with indium supplied by Hitachi. About 7-10 mg of the sample was used, and the thermograms were recorded from RT to $300{ }^{\circ} \mathrm{C}$ under $\mathrm{N}_{2}(60$ $\mathrm{mL} / \mathrm{min}$ ) at a heating rate of $10{ }^{\circ} \mathrm{C} / \mathrm{min}$. Thermogravimetric analysis (TGA) was carried out with a Hitachi STA7000 series. The instrument was calibrated with calcium oxalate and aluminum supplied by Hitachi. About $10 \mathrm{mg}$ of the samples was taken for each analysis under $\mathrm{N}_{2}(60 \mathrm{~mL} / \mathrm{min})$ and at a heating rate of $20^{\circ} \mathrm{C} / \mathrm{min}$.

Synthesis of Cardanol Benzoxazine Monomers (CDL). Synthesis of cardanol benzoxazine monomers (CDL) (Scheme 1) was carried out by the following route: about 2 moles of paraformaldehyde were mixed with 1 mole of cardanol under vigorous stirring, 1 mole of different amine compounds (aee and 3-ap) dissolved in ethyl acetate was added, and then the temperature was increased to reflux. Stirring was continued at the same temperature for $48 \mathrm{~h}$ until the mixture became homogeneous. The product obtained was diluted with EA and filtered to remove unreacted materials and the organic layer was washed 3-4 times with $1 \mathrm{~N} \mathrm{NaOH}$, followed by distilled water. The organic layer was dried over anhydrous $\mathrm{Na}_{2} \mathrm{SO}_{4}$ and then the solvent was evaporated in a rotary evaporator and the hydroxyl-terminated cardanol benzoxazine monomers were stored at RT. 
Scheme 1. Synthesis of Cardanol-Based Benzoxazine Monomers (CDL-aee and CDL-3-ap)

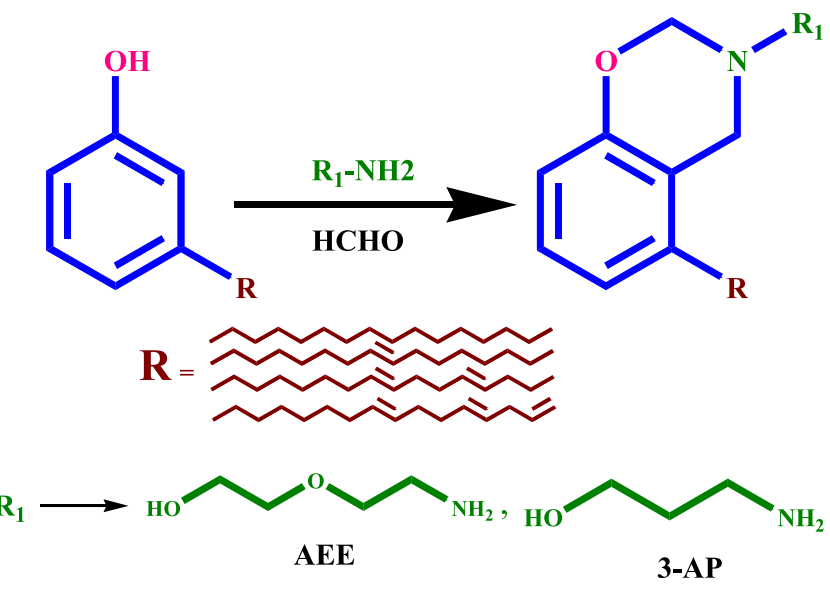

Development of Self-Healing Cardanol-Based Polybenzoxazine Matrices. Self-healing cardanol-based polybenzoxazine matrices (Scheme 2) were prepared by the simple thermal curing ring-opening polymerization technique using cardanol benzoxazine (CDL-aee and CDL-3-ap) and HMDI. In a $50 \mathrm{~mL}$ round-bottom flask, CDL-aee and CDL-3-ap (1 mole) were dissolved in $10 \mathrm{~mL}$ of 1,4-dioxane, and then HMDI in 1,4-dioxane ( 1 mole) was added slowly under a $\mathrm{N}_{2}$ atmosphere at room temperature. Further, the reaction was stirred continuously for $6-8 \mathrm{~h}$ until the solution became viscous in nature. Then, the viscous solution was poured into a silane-treated glass plate and kept overnight at $45{ }^{\circ} \mathrm{C}$ for solvent evaporation. Then, a thermal curing cycle was performed at $60,80,100,120,140$, and $160{ }^{\circ} \mathrm{C}$ for $1 \mathrm{~h}$ each and postcured at $180{ }^{\circ} \mathrm{C}$ for $2 \mathrm{~h}$. Finally, the red brown poly(U-co-CDL-aee) and poly(U-co-CDL-3-ap) films were peeled off from the Petri dish and utilized for further characterizations.

\section{ASSOCIATED CONTENT}

\section{Supporting Information}

The Supporting Information is available free of charge at https://pubs.acs.org/doi/10.1021/acsomega.0c04840.

Self-healing behavior of poly(U-co-CDL) (MP4)

\section{AUTHOR INFORMATION}

\section{Corresponding Authors}

Krishnamoorthy Krishnadevi - Polymer Composites Lab, Division of Chemistry, Department of Sciences \& Humanities, Vignan's Foundation for Science, Technology and Research (Deemed to be University), 522213 Guntur, India; ○ orcid.org/0000-0003-0256-9623; Email: krishchem05@ gmail.com

Subramani Devaraju - Polymer Composites Lab, Division of Chemistry, Department of Sciences \& Humanities, Vignan's Foundation for Science, Technology and Research (Deemed to be University), 522213 Guntur, India; Email: subudeva@ gmail.com

\section{Authors}

Salendra Sriharshitha - Polymer Composites Lab, Division of Chemistry, Department of Sciences \& Humanities, Vignan's Foundation for Science, Technology and Research (Deemed to be University), 522213 Guntur, India

Venkatesan Srinivasadesikan - Division of Chemistry, Department of Sciences and Humanities, Vignan's Foundation for Science, Technology and Research (Deemed to be University), 522213 Guntur, India

Shyi-Long Lee - Department of Chemistry and Biochemistry, National Chung Cheng University, Chia-yi 621, Taiwan

Complete contact information is available at:

https://pubs.acs.org/10.1021/acsomega.0c04840

\section{Notes}

The authors declare no competing financial interest.

Scheme 2. Schematic Representation of Ring-Opening Polymerization and Copolymerization of Poly(U-co-CDL-aee) Materials with Possible Self-Healing Ability by Supramolecular H-Bonding Interactions

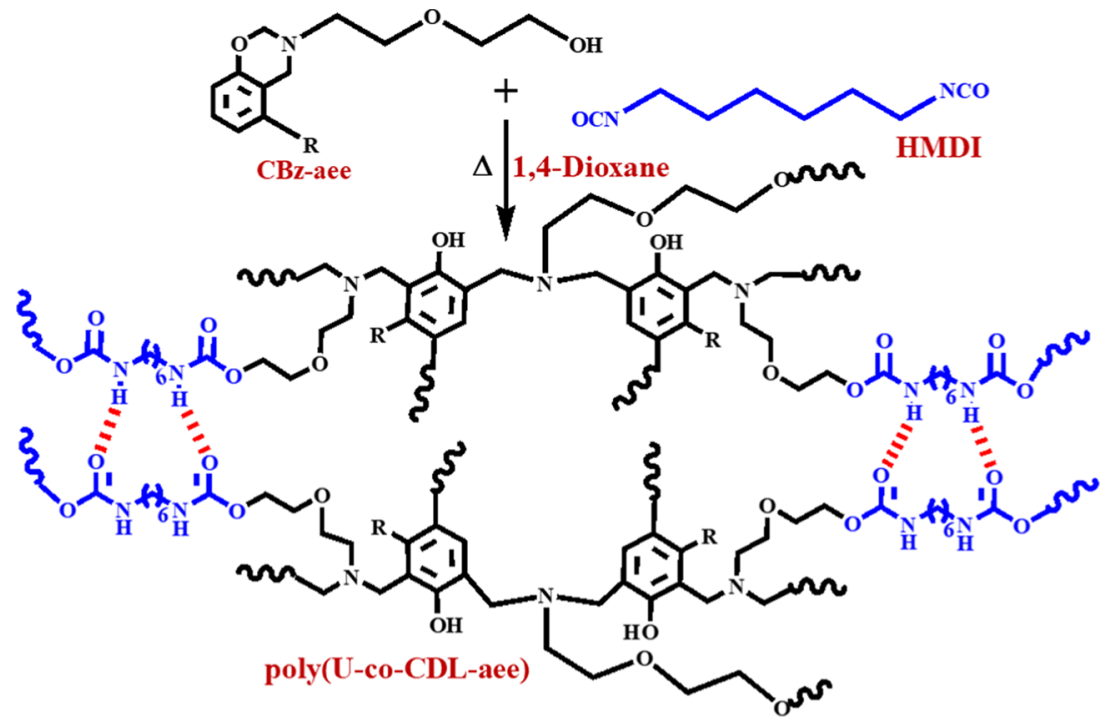




\section{ACKNOWLEDGMENTS}

One of the authors, Sriharshitha, wishes to thank VFSTR for providing funding and research facilities. Also, the authors acknowledge VIT for ${ }^{1} \mathrm{H}$ NMR characterization and CoExAMMPC for FT-IR, DSC, and TGA characterizations.

\section{REFERENCES}

(1) Ling, L.; Li, J.; Zhang, G.; Sun, R.; Wong, C. P. Self-Healing and Shape Memory Linear Polyurethane Based on Disulfide Linkages with Excellent Mechanical Property. Macromol. Res. 2018, 26, 365-373.

(2) Urdl, K.; Kandelbauer, A.; Kern, W.; Müller, U.; Thebault, M.; Rusch, E. Z. Self-healing of densely crosslinked thermoset polymersa critical review. Prog. Org. Coat. 2017, 104, 232-249.

(3) Chen, W.; Zhou, Y.; Li, Y.; Sun, J.; Pan, X.; Yu, Q.; Zhou, N.; Zhang, Z.; Zhu, X. Shape-memory and self-healing polyurethanes based on cyclic poly( $\epsilon$-caprolactone). Polym. Chem. 2016, 7, 67896797.

(4) Cao, S.; Li, S.; Li, M.; Xu, L.; Ding, H.; Xia, J.; Zhang, M.; Huang, K. A. A thermal self-healing polyurethane thermoset based on phenolic urethane. Polym. J. 2017, 49, 775-781.

(5) Liu, J.; Cao, J.; Zhou, Z.; Liu, R.; Yuan, Y.; Liu, X. Stiff SelfHealing Coating Based on UV-Curable Polyurethane with a 'hard Core, Flexible Arm' Structure. ACS Omega 2018, 3, 11128-11135.

(6) Feula, A.; Pethybridge, A.; Giannakopoulos, I.; Tang, X.; Chippindale, A.; Siviour, C. R.; Buckley, C. P.; Hamley, I. W.; Hayes, W. A Thermoreversible Supramolecular Polyurethane with Excellent Healing Ability at $45{ }^{\circ} \mathrm{C}$. Macromolecules 2015, 48, 6132-6141.

(7) Feng, L.; Yu, Z.; Bian, Y.; Lu, J.; Shi, X.; Chai, C. Self-healing behavior of polyurethanes based on dual actions of thermo-reversible Diels-Alder reaction and thermal movement of molecular chains. Polymer 2017, 124, 48-59.

(8) Arslan, M.; Kiskan, B.; Yagci, Y. Benzoxazine-based thermosets with autonomous self-healing ability. Macromolecules 2015, 48, 13291334.

(9) Salum, M. L.; Iguchi, D.; Arza, C. R.; Han, L.; Ishida, H.; Froimowicz, P. Making Benzoxazines Greener: Design, Synthesis, and Polymerization of a Biobased Benzoxazine Fulfilling Two Principles of Green Chemistry. ACS Sustainable Chem. Eng. 2018, 6, 13096-13106. (10) Kiskan, B.; Arslan, M.; Taskin, O. S.; Yagci, Y. Polybenzoxazines as Self-Healing Materials; Elsevier Inc., 2017; pp 1019-1028.

(11) Zhu, L.; Shi, T.; Zhang, L.; Qian, Y.; Yang, L. Preparation and characteristics of poly(benzoxazine-urethane)/graphene oxide composites: Toughness, mechanical and thermal properties. J. Macromol. Sci., Part A: Pure Appl. Chem. 2017, 54, 967-977.

(12) Nair, C. P. R. Advances in addition-cure phenolic resins. Prog. Polym. Sci. 2004, 29, 401-498.

(13) Takeichi, T.; Agag, T. High performance polybenzoxazines as novel thermosets. High Perform. Polym. 2006, 18, 777-797.

(14) Arslan, M.; Kiskan, B.; Yagci, Y. Recycling and self-healing of polybenzoxazines with dynamic sulfide linkages. Sci. Rep. 2017, 7, No. 5207.

(15) Arslan, M.; Kiskan, B.; Yagci, Y. Benzoxazine-Based Thermoset with Autonomous Self-Healing and Shape Recovery. Macromolecules 2018, 51, 10095-10103.

(16) Fan, W.; Zhang, Y.; Li, W.; Wang, W.; Zhao, X.; Song, L. Multilevel self-healing ability of shape memory polyurethane coating with microcapsules by induction heating. Chem. Eng. J. 2019, 368, 10331044.

(17) Ghosh, N. N.; Kiskan, B.; Yagci, Y. Polybenzoxazines-New high-performance thermosetting resins. Prog. Polym. Sci. 2007, 32, 1344-1391.

(18) Arslan, M.; Kiskan, B.; Yagci, Y. Benzoxazine-Based Thermoset with Autonomous Self-Healing and Shape Recovery. Macromolecules 2018, 51, 10095-10103.

(19) Ishida, H.; Agag, T. Overview and Historical Background of Polybenzoxazine Research. In Handbook of Benzoxazine Resins; Elsevier: Amsterdam, 2011; 3-81.
(20) Kiskan, B. Adapting benzoxazine chemistry for unconventional applications. React. Funct. Polym. 2018, 129, 76-88.

(21) Lyu, Y.; Ishida, H. Natural-sourced benzoxazine resins, homopolymers, blends and composites: A review of their synthesis, manufacturing and applications. Prog. Polym. Sci. 2019, 99, No. 101168.

(22) Ishida, H.; Agag, T. Handbook of Benzoxazine Resins; Elsevier: Amsterdam, 2011; pp 1-688.

(23) Ishida, H.; Froimowicz, P. Advanced and Emerging Polybenzoxazine Science and Technology; Elsevier: Amsterdam, 2017; pp 1-1097.

(24) Arslan, M.; Kiskan, B.; Yagci, Y. Benzoxazine-Based Thermosets with Autonomous Self-Healing Ability. Macromolecules 2015, 48, 1329-1334.

(25) Arslan, M.; Kiskan, B.; Yagci, Y. Benzoxazine-Based Thermoset with Autonomous Self-Healing and Shape Recovery. Macromolecules 2018, 51, 10095-10103.

(26) Taskin, O. S.; Kiskan, B.; Yagci, Y. Polybenzoxazine precursors As self-healing agents for polysulfones. Macromolecules 2013, 46, 8773-8778.

(27) Kiskan, B.; Yagci, Y. Self-healing of poly(propylene oxide)polybenzoxazine thermosets by photoinduced coumarine dimerization. J. Polym. Sci., Part A: Polym. Chem. 2014, 52, 2911-2918.

(28) Fu, F.; Huang, M.; Zhang, W.; Zhao, Y.; Liu, X. Thermally assisted self-healing behavior of anhydride modified polybenzoxazines based on transesterification. Sci. Rep. 2018, 8, No. 10325.

(29) Han, L.; Iguchi, D.; Gil, P.; Hey, T. R.; Sedwick, V. M.; Arza, C. R.; Ohashi, S.; Lacks, D. J.; Ishida, H. Oxazine Ring-Related Vibrational Modes of Benzoxazine Monomers Using Fully Aromatically Substituted, Deuterated, 15N Isotope Exchanged, and OxazineRing-Substituted Compounds and Theoretical Calculations. J. Phys. Chem. A 2017, 121, 6269-6282.

(30) Krishnamoorthy, K.; Subramani, D.; Eeda, N.; Muthukaruppan, A. Development and characterization of fully bio-based polybenzoxazine-silica hybrid composites for low-k and flame-retardant applications. Polym. Adv. Technol. 2019, 30, 1856-1864.

(31) Devaraju, S.; Krishnadevi, K.; Sriharshitha, S.; Alagar, M. Design and Development of Environmentally Friendly Polybenzoxazine-Silica Hybrid from Renewable Bio-resource. J. Polym. Environ. 2019, 27, 141-147.

(32) Arumugam, H.; Krishnan, S.; Chavali, M.; Alagar, M. Cardanol based benzoxazine blends and bio-silica reinforced composites: Thermal and dielectric properties. New J. Chem. 2018, 42, 40674080.

(33) Herbst, F.; Binder, W. H. Self-healing polymers via supramolecular, hydrogen-bonded networks. Macromol. Rapid Commun. 2013, 34, 203-220.

(34) Frisch, M. J.; Trucks, G. W.; Schlegel, H. B.; Scuseria, G. E.; Robb, M. A.; Cheeseman, J. R.; Scalmani, G.; Barone, V.; Mennucci, B.; Petersson, G. A.; Nakatsuji, H.; Caricato, M.; Li, X.; Hratchian, H. P.; Izmaylov, A. F.; Bloino, J.; Zheng, G.; Sonnenberg, J. L.; Hada, M.; Ehara, M.; Toyota, K.; Fukuda, R.; Hasegawa, J.; Ishida, M.; Nakajima, T.; Honda, Y.; Kitao, O.; Nakai, H.; Vreven, T.; Montgomery, J. A., Jr; Peralta, J. E.; Ogliaro, F.; Bearpark, M.; Heyd, J. J.; Brothers, E.; Kudin, K. N.; Staroverov, V. N.; Kobayashi, R.; Normand, J.; Raghavachari, K.; Rendell, A.; Burant, J. C.; Iyengar, S. S.; Tomasi, J.; Cossi, M.; Rega, N.; Millam, J. M.; Klene, M.; Knox, J. E.; Cross, J. B.; Bakken, V.; Adamo, C.; Jaramillo, J.; Gomperts, R.; Stratmann, R. E.; Yazyev, O.; Austin, A. J.; Cammi, R.; Pomelli, C.; Ochterski, J. W.; Martin, R. L.; Morokuma, K.; Zakrzewski, V. G.; Voth, G. A.; Salvador, P.; Dannenberg, J. J.; Dapprich, S.; Daniels, A. D.; Farkas, Ö.; Foresman, J. B.; Ortiz, J. V.; Cioslowski, J.; Fox, D. J. Gaussian, Inc.: Wallingford, CT, 2009.

(35) Becke, A. D. Density-functional exchange-energy approximation with correct asymptotic behavior. Phys. Rev. A 1988, 38, 3098.

(36) Becke, A. D. Density-functional thermochemistry. III. The role of exact exchang. J. Chem. Phys. 1993, 98, 5648.

(37) Becke, A. D. A new inhomogeneity parameter in densityfunctional theory. J. Chem. Phys. 1998, 109, 2092-2098. 
(38) Schmider, H. L.; Becke, A. D. Optimized density functionals from the extended G2 test set. J. Chem. Phys. 1998, 108, 9624.

(39) Srinivasadesikan, V.; Sahu, P. K.; Lee, S. L. Quantum Mechanical Calculations for the Misincorporation of Nucleotides Opposite Mutagenic 3, N4-Ethenocytosine. J. Phys. Chem. B 2012, 116, 11173-11179.

(40) Rozas, I. On the nature of hydrogen bonds: an overview on computational studies and a word about patterns. Phys. Chem. Chem. Phys. 2007, 9, 2782-2790.

(41) Hutchins, K. M. Functional materials based on molecules with hydrogen-bonding ability: applications to drug co-crystals and polymer complexes. R. Soc. Open Sci. 2018, 5, No. 180564.

(42) Goward, G. R.; Schnell, I.; Brown, S. P.; Wolfgang Spiess, H.; Kim, H.-D.; Ishida, $\mathrm{H}$. Investigation of an $\mathrm{N} \cdots \mathrm{H}$ hydrogen bond in a solid benzoxazine dimer by $1 \mathrm{H}-15 \mathrm{~N}$ NMR correlation techniques under fast magic-angle spinning. Magn. Reson. Chem. 2001, 39, S5S17. 